\title{
Helping to Combat Chronic Wasting Disease
}

\section{Collaborative efforts to address the $G$ problem of CWD - in Wisconsin and across the country - have provided some answers, but much still needs to be done.}

\section{Background}

Chronic Wasting Disease (CWD) is a disease of the nervous system that results in distinctive lesions in the brain. CWD affects elk, white-tailed deer, and mule deer, but has not been documented in livestock or humans. The cause is unknown and no treatment is available. Infected deer and elk can appear robust and healthy in the early stages of CWD; it may take several years before they show clinical signs, after which the disease is fatal. Direct contact between infected and non-infected animals is the most likely route of transmission, but other possibilities are under consideration, including contamination of soil by excreta from infected animals.

USGS is collaborating with federal, state, and private partners to address CWD issues. These joint efforts have addressed immediate needs - developing cooordinated plans, establishing diagnostic capabilities to identify the disease, modeling and analyzing effects of the disease, and

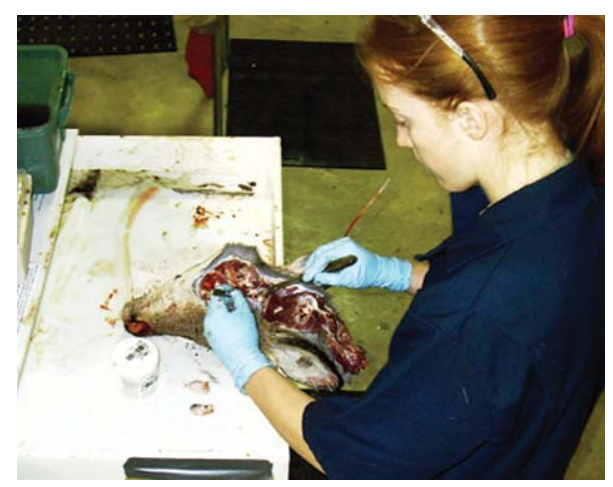

Preparing to sample lymph nodes for CWD testing at the Park Falls, Wisconsin, sampling site. Photo courtesy of Harold Rihn, Jr., USGS. providing easily accessible information to cooperators and the public - but much still needs to be done. New initiatives, based on the plans already developed, will seek to refine our information about the disease and identify effective management strategies for CWD control and eradication.

\section{National Planning and Surveillance Workshop}

The USGS National Wildlife Health Center conducted a workshop in early December, 2002, to develop strategies for detection and surveillance of Chronic Wasting Disease (CWD) in wild deer and elk. Participants came from various backgrounds (e.g. wildlife disease, cervid population biology, statistical modeling) and provided differing viewpoints and expertise, resulting in a comprehensive plan addressing many facets of the problem. A white paper is anticipated in late March and will be available in both electronic and hard copy form. The intended audience includes state and federal wildlife management agencies, tribal governments, and wildlife disease investigation and research programs.

The group identified three primary goals for a surveillance program: detection, assessment, and monitoring. Several risk factors were suggested to guide decisions of resource allocation and focus on target areas. Sampling design was determined based upon several likely scenarios of population size, species, and habitat. Strengths and weaknesses of several sample collection methods were evaluated. Implementation costs for large protracted surveillance programs were estimated

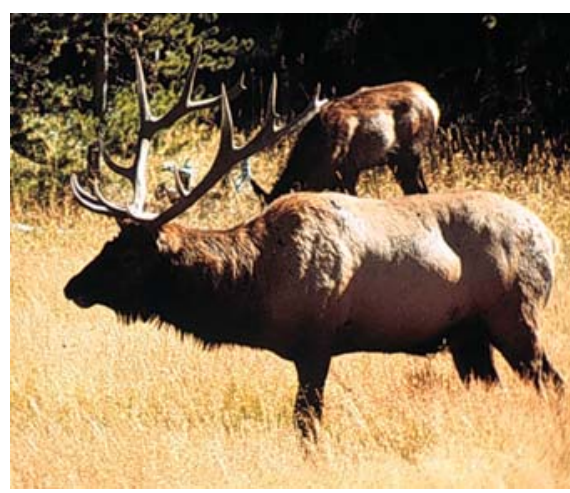

Elk. Photo courtesy of Milton Friend, USGS.

based on the varied experience of the workshop participants.

\section{Wisconsin Veterinary Diagnostic Laboratory Collaboration}

In cooperation with the Wisconsin Veterinary Diagnostic Laboratory, USGS has established a shared diagnostic laboratory for the detection of CWD in deer and elk tissues. This capability allows USGS to provide diagnostic support to the Department of Interior for this disease. Both the gold standard detection test and the high throughput test are employed. In addition, USGS pathology staff have participated in USDA sponsored training sessions, to allow them to accurately interpret results from these tests.

\section{Wisconsin Department of Natural Resources Partnership}

USGS has had a sustained role in the investigation of CWD in Wisconsin. Initially, the Center provided general information, consultation and assistance to state personnel. Staff provided guidance on surveillance plans, and analyses of results collected by implementation of the recommended plans. These analyses proved crucial to the continued assessment of the disease in the state.

USGS staff have continued to participate in team meetings on the overall Wisconsin state CWD program. Personnel are active participants on the Science and Health Team and the Research Team, providing comments, suggestions, and direct input into decisions. USGS staff also assisted with questions from the public at 6 public hearings on CWD held throughout the state. In addition, staff members 
participated in special deer harvests as part of the state-sponsored disease control program and worked in the tissue processing centers, offering their expertise to accurately collect appropriate tissues for the detection of CWD.

\section{Department of Interior and State Activities}

USGS has been contacted by several Bureaus within the Department for assistance with CWD. In addition, tribal governments - either through the Bureau of Indian Affairs or directly - have asked for training and assistance in surveillance programs. The Fish and Wildlife Service has requested and been given advice and assistance in establishing monitoring programs as well.

USGS scientists from the National Wildlife Health Center represented the Department of Interior and participated in a review of the science program proposed by the state of Colorado for the management of CWD. Review findings were presented at a two day workshop in Denver, Colorado. Scientists also participated, by invitation, in a workshop hosted by the Agricultural Research Service of the USDA, which focused on prion diseases including CWD. USGS scientists served as panelists in a special session devoted to CWD at a meeting of the United States Animal Health Association in St. Louis, Missouri. Most imporantly, USGS personnel actively participated in the development of the National Plan for the Investigation of CWD and later in the implementation plans for states, tribes and federal agencies.

\section{Information Products}

USGS personnel have worked diligently to provide accurate, up-to-date information on CWD, providing links to federal, state, foreign and private organizations' information on a web site at www.nwhc.usgs.gov, with media links, factsheets, planning documents, a CWD bibliography, questions and answers, and regularly updated maps showing the extent of the disease. In addition, the newly inaugurated Wildlife Disease Information Node (WDIN) was initiated as part of the National Biological Information Infrastructure to serve as a focal point for information on diseases in wild animals, offering near real-time prevalence reporting. A strong initial focus will be on Chronic Wasting Disease, where all current web based information will be organized and annotated. The WDIN will also serve as a central repository for CWD testing results generated by state, tribal and federal agencies.

\section{New Initiatives and Future Directions}

Collaborative research studies with the Wisconsin DNR and University of Wisconsin have been initiated to enhance scientific knowledge about CWD and to assist in the development of management strategies. Research focuses on better understanding how CWD is transmitted among white-tailed deer, understanding the pattern of infection on the landscape, and determining the susceptibility of different age/sex classifications of deer to infection. Results will be used to develop improved modeling and quantitative tools to help predict the spread of CWD and help evaluate management actions

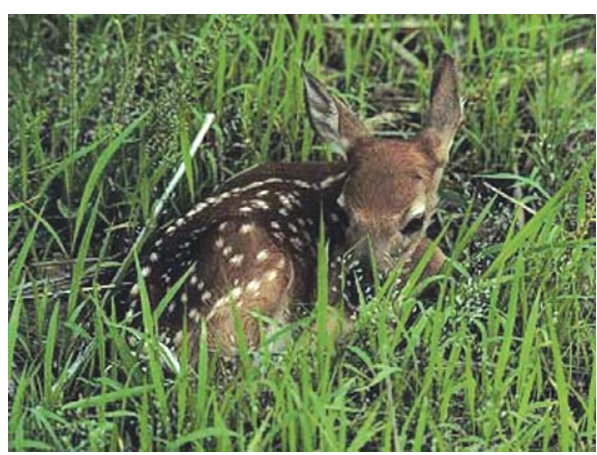

White-tailed deer fawn. Photo courtesy of Wellesley College.

to control or eradicate this disease. Collaborative research studies at Iowa State University have been initiated to assist in developing statistical tools to improve and assess surveillance programs that will be employed to determine if CWD is present on the landscape, assess the distribution and prevalence of new disease foci, and to monitor changes in disease prevalence in established disease areas.

Technical assistance for state agencies and units of the FWS that might become affected by CWD is expected to increase in 2003. USGS scientists in the Central Region are planning to investigate the relationship of deer and elk population ecology to CWD as a basis for future management recommendations.

A better understanding of the dynamics of the disease is critical to effective management strategies. The ongoing collaboration between federal, state and tribal governments, and private organizations, offers the best possibility of identifying disease parameters and developing successful control measures.

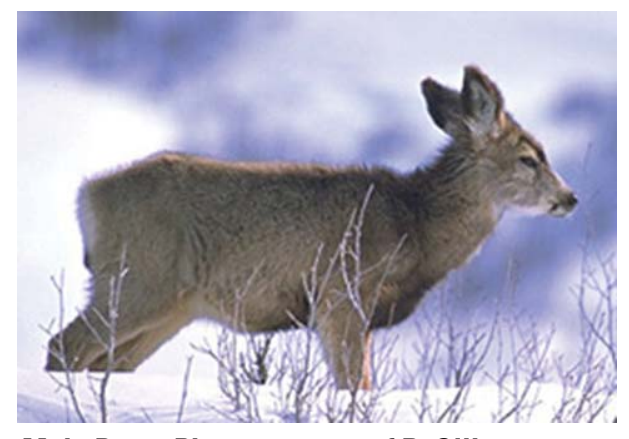

Mule Deer. Photo courtesy of B. Gill.
For more information on Chronic Wasting Disease, please contact Dr. Scott Wright, USGS National Wildlife Health Center, (608) 270-2460, or Mr. Paul Slota, USGS National Wildlife Health Center, (608) 270-2420. 